Document downloaded from:

http://hdl.handle.net/10251/169151

This paper must be cited as:

Bermúdez, V.; García Martínez, A.; Villalta-Lara, D.; Soto, L. (2020). Assessment on the consequences of injection strategies on combustion process and particle size distributions in Euro VI medium-duty diesel engine. International Journal of Engine Research. 21(4):683697. https://doi.org/10.1177/1468087419865652

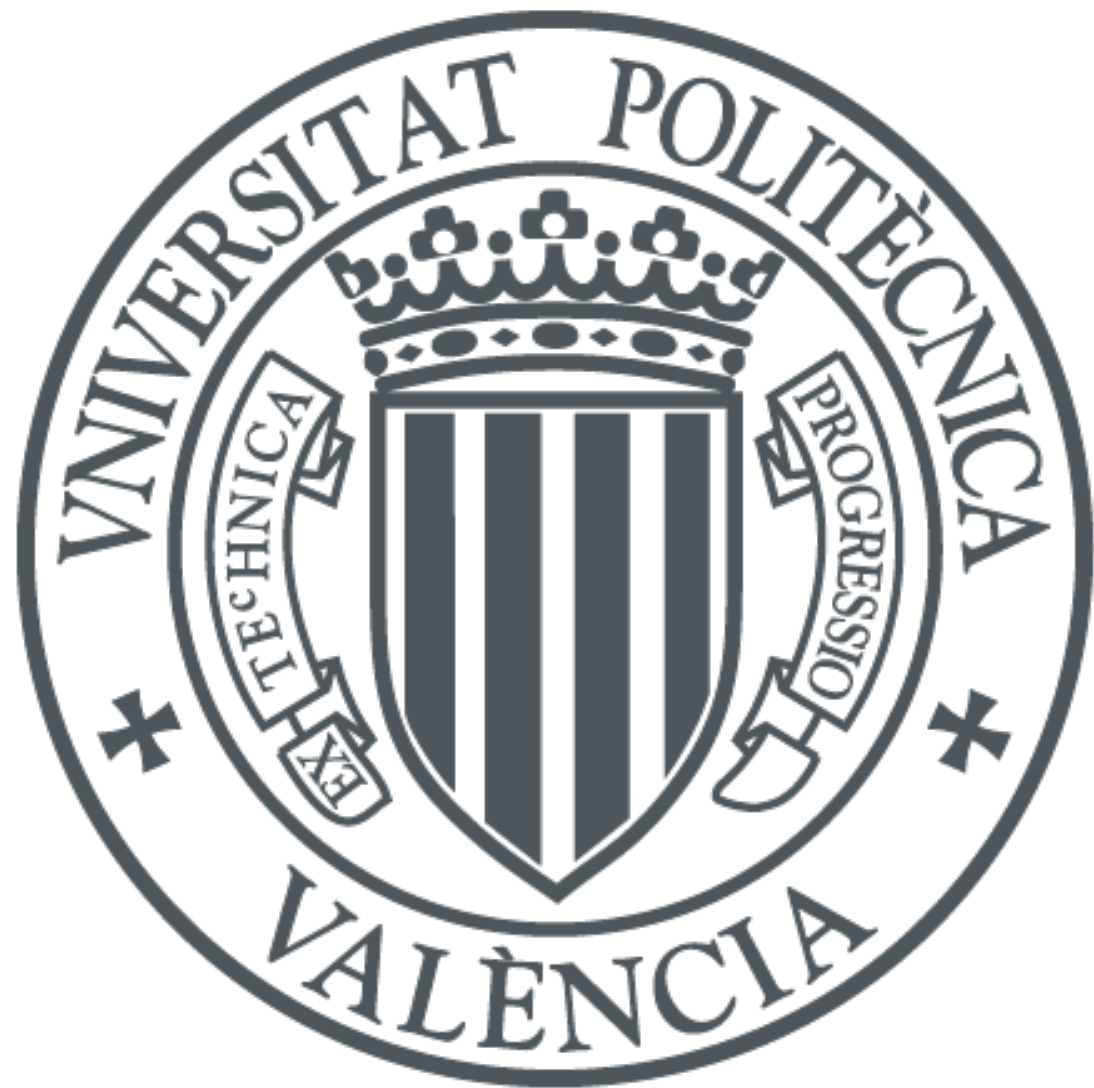

The final publication is available at

https://doi.org/10.1177/1468087419865652

Copyright SAGE Publications

Additional Information

This is the author's version of a work that was accepted for publication in International Journal of Engine Research. Changes resulting from the publishing process, such as peer review, editing, corrections, structural formatting, and other quality control mechanisms may not be reflected in this document. Changes may have been made to this work since it was submitted for publication. A definitive version was subsequently published as https://doi.org/10.1177/1468087419865652. 


\title{
Assessment on the consequences of injection strategies on combustion process and particle size distributions in Euro VI medium-duty diesel engine.
}

\author{
Vicente Bermúdez*, Antonio García, David Villalta, and Lian Soto \\ Universitat Politècnica de València, CMT-Motores Térmicos, Camino de Vera s/n, 46022 Valencia, Spain. \\ *Corresponding author. Tel.: +34 96387-9652; E-mail: bermudez@mot.upv.es
}

\begin{abstract}
Although there are already several works where the influence of injection parameters on exhaust emissions, and specifically on particulate matter emissions in diesel engines has been evaluated, the diversity in the results that can be found in the literature indicates the need to carry out new experiments that can provide more information about the influence of these parameters on modern diesel engines. This study intends to be placed within this scientific framework, hence a parametric study was carried out based on the independent modification of the main injection timing and the injection pressure with respect to the nominal conditions of a new Euro VI direct injection diesel engine. Four steady-state operation points of the engine map were chosen: $25 \%$ load and 950 rpm, 50\% load and $1500 \mathrm{rpm}, 75 \%$ load and $2000 \mathrm{rpm}$, and 100\% load and $2200 \mathrm{rpm}$, where in each of these operation points, the variations of the injection parameters in the study on the combustion process and its consequent impact on the particle size distribution, including an analysis of the geometric mean diameter values, were evaluated. The results showed that the different injection strategies adopted, despite not significantly affecting the engine efficiency, did cause a significant impact on particle number emissions. At the low load operation, the size distribution showed a bimodal structure and, as the main injection timing was delayed and the injection pressure decreased the nucleation-mode particle concentration decreased while the accumulationmode particle concentration increased. Additionally, at medium load, the nucleation-mode particle emission decreased considerably while the accumulation-mode particle emission increased, and this increase was much greater with the main injection timing delay and the injection pressure reduction. Similar behavior was observed at high load but with a much more prominent pattern.
\end{abstract}

Keywords: modern diesel engine, particle size distribution, particle number emissions, injection strategies

\section{Abbreviations}

CA crank angle

CA90-CA10 combustion duration

CDC conventional diesel combustion

DI direct injection

ECU engine control unit

EGR exhaust gas recirculation

GIE indicated gross efficiency

GMD geometric mean diameter

ICE internal combustion engine

IMEP indicated mean effective pressure

IP injection pressure

Mix. Time mixing time

MCE multi cylinder engine

$\begin{array}{ll}\mathrm{m}_{\text {fuel }} & \text { fuel mass flow } \\ \text { NOx } & \text { nitrogen oxides } \\ \text { Pcyl } & \text { in-cylinder pressure } \\ \text { PN } & \text { particle number } \\ \text { PM } & \text { particulate matter } \\ \text { PSD } & \text { particle size distribution } \\ \text { RoHR } & \text { rate of heat release } \\ \text { SCE } & \text { single cylinder engine } \\ \text { SI } & \text { spark ignition } \\ \text { SoC } & \text { start of combustion } \\ \text { SOI } & \text { start of injection }\end{array}$

T. Bulk Max maximum bulk gas temperature TDC top dead center 


\section{Introduction}

Despite the positive attributes of direct injection (DI) diesel engines in terms of efficiency and durability, they are in a detrimental situation compared to spark ignition (SI) gasoline engines due to their high nitrogen oxide (NOx) emission; a gaseous compound that contributes to the formation of the tropospheric ozone, ${ }^{1}$ and due to its particulate matter (PM) emission, it is associated with the development of acute and chronic health conditions. ${ }^{2,3}$ This situation has led to the establishment of increasingly stringent regulations for pollutant emissions from the internal combustion engines (ICEs), including a significant evolution in the maximum permissible limits of PM emissions in recent years. ${ }^{4}$

In order to comply with the emission limits imposed by current regulations, some technologies have been developed that are designed to improve the combustion process in diesel engines, with the aim of achieving a better balance in terms of emissions and efficiency.

Among the measures taken to reduce pollutants emission are the modification of fuel composition, ${ }^{5-7}$ the adjustment of engine operating parameters and, simultaneously or alternatively, the application of aftertreatment systems. ${ }^{8,9}$ Other techniques used are intended to limit the conditions in which the process of the formation of some pollutants is favored, such as exhaust gas recirculation (EGR) ${ }^{10,11}$ The main current strategies aimed at reducing emissions from the DI diesel engine are based on the redesign of the engines and the modification of the operating parameters. These strategies aim to improve the air-fuel mixture process, with the consequent increase in the performance of the combustion process and the reduction of pollutant emissions. Within these strategies are the design of the combustion chamber geometry and advances in the injection system, such as multiple injection strategies, control of the injection pressure (IP) $)^{12,13}$ and the injection timing. ${ }^{14,15}$

Over the last few years, much of the scientific attention devoted to the study of pollutant emissions from ICEs has focused on the analysis of PM emissions. This has occurred as a result of the inclusion of maximum limits for the particle number (PN) concentration in the latest European Union legislations as a new metric. ${ }^{16}$ In this context, the particulate matter from ICEs are often a combination of solid particles and condensed semivolatile material with different characteristics or properties that vary in size, shape, surface, chemical composition, solubility and origin. The diversity in the composition of these particles is due to the different phenomena that give rise to the PM formation both during the combustion process and during the cooling process of the exhaust gas.

Taking into account this diversity of particles, both in size and in chemical composition, the particle size distribution (PSD) is presented as an excellent alternative to analyze the particle concentrations in the exhaust aerosol of an ICE. The PSDs are generally log-normal and bimodal in structure, with sizes ranging from nanometers to microns. ${ }^{17}$ The two modes present in the PSDs are called nucleation and accumulation, respectively. The nucleation-mode is mainly made up of condensed volatile or semi-volatile material, that can nucleate to form new particles with a greater mass, and may also contain some solid carbon and metal compounds. ${ }^{18,19}$ The formation process of these particles occurs mainly due to low combustion temperatures or during dilution and cooling of the exhaust flow. ${ }^{20,21}$ The nucleation-mode is made up of particles with a diameter range of 5 to $30 \mathrm{~nm}^{22}$, while the accumulation-mode is composed of particles that have a diameter in the range of $30 \mathrm{~nm}$ to $1 \mu \mathrm{m} .{ }^{23}$ These particles are mainly agglomerated of soot primary particles, on whose surface there is volatile material which is absorbed. ${ }^{24,25}$ The high combustion temperature and rich equivalence ratio zones are the two main factors that favor the formation process of soot particles and can occur both in premixed and non-premixed combustion. The formation of the first precursors and their evolution to the final solid particles is mainly based on the following steps: pyrolysis, nucleation, surface growth, agglomeration and oxidation, in the works of Reijnders et al. ${ }^{26}$ and Bonatesta et $a l .{ }^{27}$ this evolution process is described in detail.

Despite the fact that gaseous emissions and particle mass from diesel engines have been reduced progressively by the adequate application of engine modifications, there is increasing concern regarding whether current engine modifications applied to improve combustion and reduce emissions are increasing the number and/or reducing the size of the emitted particles. In this sense, the evolution of injection parameters has had a significant influence on PN emissions. This can be explained follows with the fact that, in DI diesel engines, the combustion process and, consequently, the formation of the particles are closely coupled to the injection process, injection timing and injection pressure.

This concern arises from some experimental studies, among which are those of Baumgard et al. ${ }^{28}$ and Bertola et al $^{29}$ in which an increase in the number of particles was observed from the implementation of 
advanced systems of high-pressure injection and of the injection timing control. As a result, further investigations have been published concerning the effect of some injection strategies on particle size distribution. ${ }^{30-32}$ Several hypotheses have been formulated to explain the increased number of particles observed in new diesel engines, and it is thought that there are two major causes: a higher concentration of volatile nanoparticle precursors, and a decrease in mass of accumulation mode particles.

Considering the previously described background, the motivation and objective of this work is to further understand the effect of different injection strategies on PN emission from a modern medium-duty diesel engine. For this, a parametric study based on the independent modification of the injection timing and the injection pressure was carried out in four steady-state operation points of the engine map. At each operation point, the effect of the variation of each injection parameter under study on the combustion process and its consequent impact on particle size distribution and geometric mean diameter (GMD) was analyzed. Finally, a compartment between the four operation points was made, in order to understand how the load and engine speed affect the PN emissions.

\section{Material and methods}

\subsection{Test cell and engine description}

The experiments presented in this work are conducted in a single-cylinder engine. By contrast, the engine is not a conventional single cylinder engine (SCE) engine research engine, it is a hybrid solution between a multi cylinder engine (MCE) and a SCE. Indeed, this solution allows the use of a single-cylinder engine but with a more cost-effective way to implement this type of engines. The single-cylinder engine used derives from a commercial medium-duty diesel engine. The stock engine is a VOLVO D5K with 4 in-line cylinders developed for urban freight distribution purposes. Main specifications of the engine are shown in Table 1. Thus, a dedicated work has been carried out in order to split the engine in two parts. The main objective is to isolate the first cylinder operation from the rest of the engine. Hence, the stock hardware configuration has been modified in order to operate the first cylinder as SCE and the other 3 cylinders with the stock configuration.

Table 1. Main characteristics of the base engine.

\begin{tabular}{|c|c|}
\hline Characteristic & Value \\
\hline Style & 4 stroke, DI diesel engine \\
\hline OEM EVO calibration & EURO VI \\
\hline Maximum power & 177 kW@2200 rpm \\
\hline Maximum brake torque & 900 Nm@1200-1600 rpm \\
\hline Maximum in-cylinder pressure & 190 bar \\
\hline Maximum injection pressure & 2000 bar \\
\hline Bore x Stroke & $110 \mathrm{~mm} \times 135 \mathrm{~mm}$ \\
\hline Connecting rod length & $212.5 \mathrm{~mm}$ \\
\hline Crank length & $67.5 \mathrm{~mm}$ \\
\hline Total displaced volume & $5100 \mathrm{~cm} 3$ \\
\hline Number of cylinders & 4 \\
\hline Compression ratio & $15.3: 1$ \\
\hline
\end{tabular}

From the engine operation standpoint, both engines are operated at the same time. In the SCE, the combustion process analysis and the PN emission measurements are carried out, while in the other 3 cylinders are driven by the original engine control unit (ECU) with the aim to balance the cylinder-to-cylinder maximum pressure and load. With this method of engine operation, it is expected to preserve the engine integrity avoiding excessive internal stress at the crankshaft that could break it. Similar engine configurations are found in Benajes et $a l .{ }^{33}$ and Kakaee et $a l .{ }^{34}$ 


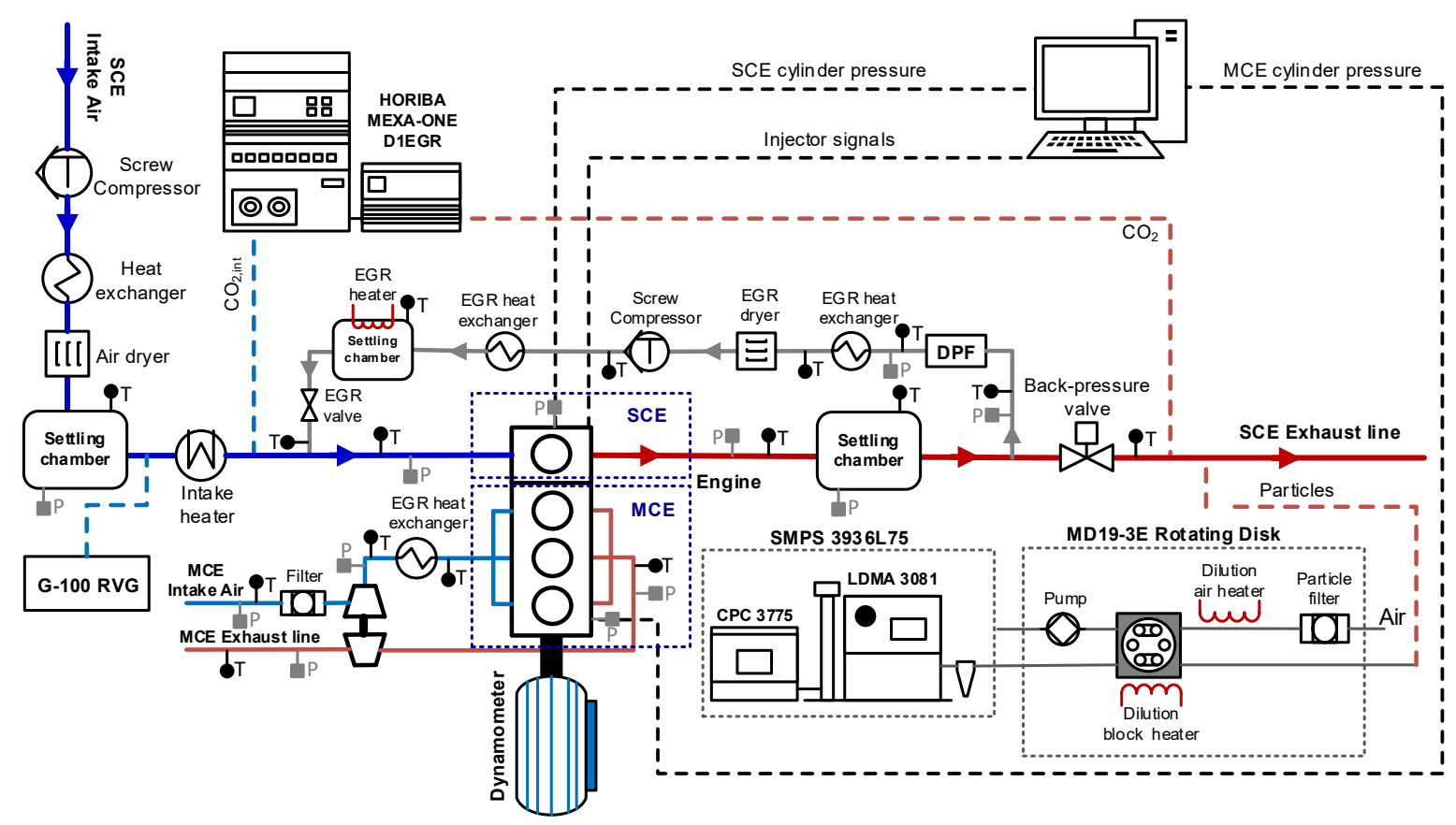

Fig. 1. Scheme of the test bench.

Fig. 1 presents the scheme of the test bench, including the engine and all the equipment required to carry out the test campaign. From the figure, it is seen that the after-treatment system has been removed, and the SCE is not using the stock turbocharger system or the stock short route high pressure (HP)-EGR. Thus, a fresh air loop and a cooled low pressure (LP) EGR loop has been coupled to provide the desired air management conditions at the SCE. The intake required fresh air is provided by a screw compressor that provides compressed air from 1 to 3.7 bar. After the dryer, the exact air mass flow is measured by means of a volumetric flow meter (G-100 RVG). The exhaust line is equipped with a back-pressure valve that generates the exhaust pressure desired by the engine operation point. This back-pressure valve contributes to the LP-EGR loop as well. Between the valve and the exhaust pipes it is located a settling chamber in order to mitigate the pressure pulses generated by the SCE. The size of the settling chamber is the same as the settling chamber placed at the intake line. The test bench was fully equipped with $\mathrm{K}$ thermocouples and mean pressure sensors in the exhaust, cooling, intake and lubricating system. Finally, the engine was connected to an AVL-APA 404 asynchronous dynamometer.

With regard to the injection system, a common-rail injection system with a solenoid injector was used to inject the diesel fuel directly into the SCE. The common rail is a typical common rail but with only one line available for one single injection, the pressure sensor and the return line. The injector has a 7-hole nozzle and the maximum injection pressure of the system is 2000 bar. Main properties of the diesel injector are presented in Table 2. The fuel mass flow is measured by an AVL 733S fuel balance. The injection system was governed using an in-house developed LabVIEW control system implemented on Drivven hardware.

Table 2. Diesel direct injector characteristics.

\begin{tabular}{ll}
\hline Characteristic & Value \\
\hline Actuation type & Solenoid \\
Steady flow rate @ $\mathbf{1 0 0}$ bar $\left[\mathbf{c m}^{3} / \mathbf{m i n}\right]$ & 1300 \\
Number of holes & 7 \\
Hole diameter $[\boldsymbol{\mu m}]$ & 177 \\
Included spray angle $\left[{ }^{\circ}\right]$ & 150 \\
Maximum injection pressure $[\mathbf{b a r}]$ & 2000 \\
\hline
\end{tabular}

The fuels used during the experiments were obtained directly from the regular petrol stations. Main physicochemical properties are presented in Table 3. 
Table 3. Physical and chemical properties of the diesel fuel.

\begin{tabular}{ll}
\hline Properties & Value \\
\hline Density $\left[\mathrm{kg} / \mathbf{m}^{\mathbf{3}}\right]\left(\mathbf{T}=\mathbf{1 5}^{\circ} \mathbf{C}\right)$ & 820 \\
Viscosity $\left[\mathbf{c m}^{\mathbf{2}} / \mathbf{s}\right]\left(\mathbf{T}=\mathbf{4 0}^{\circ} \mathbf{C}\right)$ & 2.8 \\
Oxidation stability $[\mathbf{m i n}]$ & 1200 \\
Flash point $\left[{ }^{\circ} \mathrm{C}\right]$ & $>55$ \\
Cetane number [-] & $>51$ \\
Lower heating value $[\mathbf{M J} / \mathbf{k g}]$ & 42.97 \\
\hline
\end{tabular}

The Horiba-MEXA-ONE-D1-EGR was used to measure the $\mathrm{CO}_{2}$ concentrations and consequently the EGR rate. This measuring instrument has non-dispersive infrared detector (NDIR). The technique used is based on wavelength of infrared light absorption. Both gaseous compounds absorb a known wavelength that is converted into concentration values.

A single-stage dilution system was coupled with a scanning mobility particle sizer (SMPS) to measure particle size distributions (PSD). The dilution system used in this study was an MD19-3E Rotating Disk, which uses a unique rotating disk method to dilute a sample for particle measurement. Two disks, one with eight and the other with ten cavities allows to select a dilution ratio from 15:1 to 3000:1. A portion of the raw exhaust is captured by each cavity of the rotating disk and is mixed with preheated and filtered dilution air.

In the MD19-3E RD, the dilution unit and the dilution air can be heated up to selectable temperatures of $200{ }^{\circ} \mathrm{C}$. This method keeps liquids evaporated above their dew point, during and after dilution, and prevents generation of volatile nanoparticles by nucleation. This thermal conditioning of the sample allows for the reduction of the concentration range within the acceptable limits of the particle measuring device and provides accurate information on the concentration of particles generated during the combustion process. The advantages of this dilution system can be analyzed in more detail in previous study by the authors Kasper et al. ${ }^{35}$

TSI Scanning Particle Sizer (SMPS 3936L75) was used to measure the PSD. This system is equipped with an inertial impactor to remove particles larger than $1 \mu \mathrm{m}$; as well as a Long Differential Mobility Analyzer (LDMA 3081) to select the particle size to be measured, with a range from 2.5 to $1000 \mathrm{~nm}$ and a Condensation Particle Counter (CPC 3775) to count particles with sizes down to $4 \mathrm{~nm}$. The accuracy of the instrumentation used in the test cell is summarized in Table 4.

Table 4. Accuracy of the instrumentation used in the test cell.

\begin{tabular}{l|l|l|l}
\hline Device & Manufacturer and model & Variable measured & Accuracy \\
\hline Air flow meter & Elster RVG G100 & Fresh air mass flow & $\pm 0.1 \%$ \\
Fuel balance & AVL 733S & Fuel mass flow & $\pm 0.2 \%$ \\
Gas analyzer & Horiba MEXA-ONE-D1-EGR & $\mathrm{CO}_{2}$ & $4 \%$ \\
SMPS & TSI SMPS-3936L75 & Particles number and size & $3.5 \%$ \\
Piezoelectric transducer & Kistler 6125C & In-cylinder pressure & $\pm 1.25 \mathrm{bar}$ \\
Piezoelectric transducer & Kistler 4045A10 & Intake/exhaust pressure & $\pm 25 \mathrm{mbar}$ \\
Thermocouple & TC direct type K & Intake/exhaust tmperature & $\pm 2.5^{\circ} \mathrm{C}$ \\
\hline
\end{tabular}

The dilution ratio and dilution air temperature affect the gas-to-particle conversion in the measurements. A significant reduction of both parameters can increase the phenomena of nucleation and adsorption/condensation of volatiles. In this sense, an increase in the total concentration of nucleation-mode particles could occur under these conditions since these particles are constituted mainly by volatile condensed material. Additionally, the size of the accumulation-mode particles could increase due to the absorption of volatile condensates on their surface.

To reduce the problems mentioned above, the measurement methodology described by Desantes et al. in steady-state operation conditions ${ }^{36}$ and also applied under transient conditions ${ }^{37}$ was used in this work. Such measurement procedure was developed to reduce the sensitivity of particle size measurements due to different dilution settings. In this sense, the dilution ratio used in this study was 30 and the dilution air temperature was $200{ }^{\circ} \mathrm{C}$.

\subsection{Theoretical tools and calculations method}


The PSD can be described as the combination of two individual distributions (nucleation-mode and accumulation-mode) assuming the log-normal size distribution, according to equation (1). ${ }^{17}$ Where $x$ is the ratio of the total concentrations number of two distributions, $\mathrm{d}_{\mathrm{p} 1}, \mathrm{~d}_{\mathrm{p} 2}, \mathrm{~d}_{\mathrm{pg} 1}, \mathrm{~d}_{\mathrm{pg} 2}, \sigma_{1}$ and $\sigma_{2}$ are the geometric mean diameters, median diameters, and geometric standard deviations of each peak, and $\mathrm{N}_{\mathrm{i}}$ is the PN of particle size $\mathrm{d}_{\mathrm{pi}}$.

$$
\frac{d N_{i}}{d \log d p_{i}}=\frac{1-x}{\sqrt{2 \pi} \log \sigma_{g 1}} \cdot e^{-\frac{\log ^{2}\left(\frac{d p_{1}}{d p_{g 1}}\right)}{2 \log ^{2} \sigma_{g 1}}}+\frac{x}{\sqrt{2 \pi} \log \sigma_{g 2}} \cdot e^{-\frac{\log ^{2}\left(\frac{d p_{2}}{d p_{g 2}}\right)}{2 \log ^{2} \sigma_{g 2}}}
$$

To calculate total particle number concentration and GMD for each mode, the equations (2) and (3) were used:

$$
\begin{aligned}
& d N=\sum_{d p(\text { low })}^{d p(\text { up })} d N_{i} \\
& G M D=\frac{\sum_{d p(\text { low })}^{d p(\text { up })} d N_{i} \ln d p_{i}}{d N}
\end{aligned}
$$

The EGR rate is obtained taking in account the $\mathrm{CO}_{2}$ at the intake and at the exhaust and the atmospheric content of $\mathrm{CO}_{2}$. Hence, the EGR rate is calculated according to equation (4), where $\mathrm{CO}_{2 \text { atmospheric }}$ is equal to 400 ppm. $\mathrm{CO}_{2}$ concentration at the intake air at the exhaust are introduced in ppm.

$$
E G R[\%]=\frac{\mathrm{CO}_{\text {2intake }}-\mathrm{CO}_{2 \text { atmospheric }}}{\mathrm{CO}_{\text {2exhaust }}-\mathrm{CO}_{2 \text { atmospheric }}} \cdot 100
$$

The combustion analysis was carried out with an in-house 0-D thermodynamic model called CALMEC. The theoretical principles of this 0-D model are based on applying the first law of thermodynamics to solve open systems considering the fuel injection and blow-by flow. This diagnostic model uses the in-cylinder pressure signal and the mean variables recorded during the experiments (engine speed, coolant, oil, intake and exhaust temperatures, air, EGR and fuel mass flow) as its main inputs, to obtain a wide variety of combustion parameters, such as the rate of heat release (RoHR), maximum bulk gas temperature (T. Bulk Max), main combustion phases (CA10, CA50 and CA90: crank angle after top dead center (CA aTDC) in which the 10\%, $50 \%$, and $90 \%$ of the total heat release has been released during the combustion process, respectively), indicated mean effective pressure (IMEP) and indicated gross efficiency (GIE). The full description of the model can be found in Pairy et al. ${ }^{38}$

In addition, the combustion duration (CA90-CA10) was determined, which is defined as the time elapsed from the start of combustion ( $\mathrm{SoC}$ ) (represented by the CA10) up to the end of the combustion (represented by the CA90). The diesel mixing time (Mix. Time) was also calculated through equation (5). As can be seen in the equation, this parameter determines the interval between the end of fuel injection (EoI) of the last diesel injection and the SoC. It is important to consider that an increase in Mix. Time positive values, results in leaner equivalence ratios at SOC. However, negative values indicate the coexistence of fuel injection and the combustion process during a certain period, which will be higher while the Mix. Time are lower (or greater in absolute value).

$$
\text { Mix.Time }=S o C-\text { EoI }_{\text {last }} \text { injection }
$$

\subsection{Test design and measurement methodology}

In order to assess a detailed analysis of PN emission in a wide range of engine speed and load, four steadystate operation points were tested. Thus, these engine operation points were selected according to fuel mass flow $\left(\mathrm{m}_{\text {fuel }}\right)$ map, obtaining a representative operation points including fuel enrichment at different levels as Fig. 2 shows. 


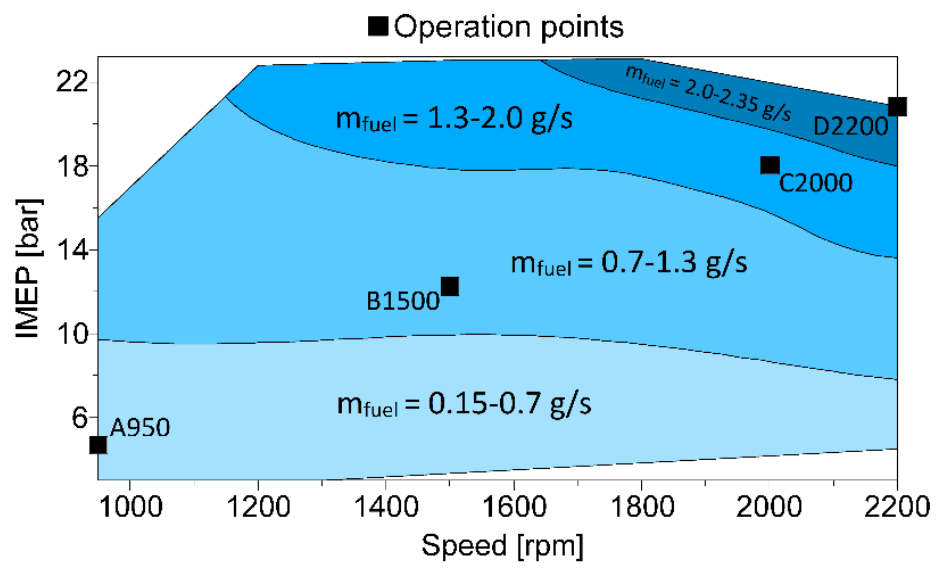

Fig. 2. Fuel mass flow map. Steady-state operation points selected.

A parametric study was carried out based on the independent modification of the IP and main injection timing from a reference operation point. The main characteristics of these operation points are shown in Table 5 , where the reference point settings are indicated in bold and the injection timing corresponds to the start of injection (SOI). The operation modes are denoted as A950, B1500, C2000 and D2200. With the exception of D2200 operation point, a double injection strategy was used, with a fixed fuel mass flow $\left(\mathrm{m}_{\text {fuel }}\right)$ which provided the required IMEP target at each operation mode. The $\mathrm{SOI}_{\text {pilot }}$ was not analyzed due to its reduced impact on the PN emissions. The air mass flow $\left(\mathrm{m}_{\text {air }}\right)$ and EGR rate were kept constant at each operation point, avoiding their influence on the combustion process and particle emissions.

Table 5. Experimental plan for the parametric study

\begin{tabular}{lllllllll}
\hline Operation point & $\begin{array}{l}\text { load } \\
{[\%]}\end{array}$ & $\begin{array}{l}\text { Speed } \\
{[\mathrm{r} / \mathrm{min}]}\end{array}$ & $\begin{array}{l}\mathbf{S O I}_{\text {pilot }} \\
{[\mathrm{CA} \text { aTDC }]}\end{array}$ & $\begin{array}{l}\mathbf{S O I}_{\text {main }} \\
{[\mathrm{CA} \text { aTDC }]}\end{array}$ & $\begin{array}{l}\text { IP } \\
{[\mathrm{b} a r]}\end{array}$ & $\begin{array}{l}\mathbf{m}_{\text {fuel }} \\
{[\mathrm{g} / \mathrm{s}]}\end{array}$ & $\begin{array}{l}\mathbf{m}_{\text {air }} \\
{[\mathrm{g} / \mathrm{s}]}\end{array}$ & $\begin{array}{l}\text { EGR } \\
{[\%]}\end{array}$ \\
\hline $\mathbf{A 9 5 0}$ & $\mathbf{2 5}$ & $\mathbf{9 5 0}$ & $\mathbf{- 5}$ & 0 & $\mathbf{8 0 0}$ & $\mathbf{0 . 2 4}$ & $\mathbf{1 0 . 8 1}$ & $\mathbf{1 4}$ \\
& & & & $\mathbf{2}$ & 1000 & & & \\
& & & & 4 & 1200 & & & \\
\hline B1500 & $\mathbf{5 0}$ & $\mathbf{1 5 0 0}$ & $\mathbf{- 1 2}$ & $\mathbf{- 3}$ & 800 & $\mathbf{0 . 9 0}$ & $\mathbf{3 4 . 4 1}$ & $\mathbf{1 0}$ \\
& & & & 0 & 1000 & & & \\
& & & & 3 & $\mathbf{1 2 0 0}$ & & & \\
\hline C2000 & $\mathbf{7 5}$ & $\mathbf{2 0 0 0}$ & $\mathbf{- 2 5}$ & $\mathbf{- 1 3}$ & 1000 & $\mathbf{1 . 5 5}$ & $\mathbf{5 4 . 1 9}$ & $\mathbf{1 4}$ \\
& & & & -9 & $\mathbf{1 2 0 0}$ & & & \\
& & & & -7 & 1400 & & & $\mathbf{1 0}$ \\
\hline D2200 & $\mathbf{1 0 0}$ & $\mathbf{2 2 0 0}$ & - & -25 & 1000 & $\mathbf{2 . 2 4}$ & $\mathbf{5 9 . 7 3}$ & $\mathbf{1 0}$ \\
& & & & -20 & $\mathbf{1 2 0 0}$ & & & \\
\hline
\end{tabular}

\subsubsection{Experimental procedure methodology}

The operation of a SCE is a complex process when every engine parameter needs to be under control. Indeed, every process such as cooling or lubrication system are usually critical in this kind of test facilities. In particular, the non-research origin of the SCE used in the current investigation implies an extra at the complexity of the tests execution. Therefore, it is very important to define a specific methodology to identify and rapidly detect possible sources of experimental errors before and during test execution. The proposed monitoring and detection protocol has been adapted from the methodology proposed in the work of Benajes et al. ${ }^{39}$ In Fig. 3 can be observed a scheme of the methodology followed along the present work. 


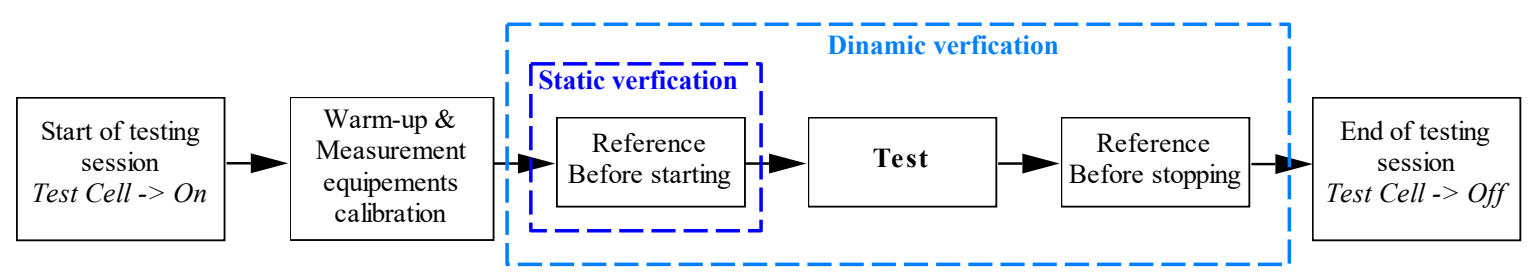

Fig. 3. Experimental procedure methodology.

As it is observed, the methodology provides two steps of verification. First step consists of a static verification and the second one consists of a dynamic verification.

- Static verification: This step consists of selecting a reference engine operation point with the aim of checking the correct operation of the different systems integrated in the experimental facility every testing day. For this purpose, the values of different parameters such as emissions, engine torque, maximum incylinder pressure, fuel supply and the fuel injection system are compared to the values measured in previous days. This verification is carried out once the engine has been heated-up. All the variables should be inside a confidence interval before proceeding with the tests campaign of the day.

- Dynamic verification: During the execution of the tests, the equipments can suffer a failure or can require a new calibration. Thus, in order to avoid this kind of dispersion or lack of reliability, the second step of verification is needed. This step will focus on the air management of the engine (fresh air mass flow, EGR rate, ...). Hence, the reference point will be set again and the main parameters will be compared. Other errors such as mean variables measured, emissions are also checked. If the dispersion observed is inside the control limits, the tests are considered as correct.

\section{Results and discussion}

\subsection{Influence of main injection timing (SOI $m a i n)$}

Before beginning the analysis of the effect of the SOI main variation over the PSD, it is interesting to take into account some important considerations in relation to the conventional diesel combustion (CDC) process.

Fig. 4 shows the combustion development through the RoHR profile and the in-cylinder pressure (Pcyl) for each SOImain at each operation point. At the D2200 operation point (Fig. 4 (d)) a typical ROHR profile of a single injection strategy near TDC with a sufficiently long duration is observed. From Fig. 4 (d), it is possible to identify the first stage or phase considered as the ignition delay, which covers the period between SOImain and SoC; or more explicitly between the time at which the first fuel droplet enters the combustion chamber environment and the time where the energy release starts to grow significantly. During this phase, the fuel is injected with no apparent or very little increase in the RoHR. The second phase is the premixed combustion. This stage is characterized by the oxidation of the fuel injected during the ignition delay because it has not reached the proper conditions for autoignition. During this phase, the RoHR achieves the first peak and then the curve decreases up to a relative minimum, which determines the next combustion phase. The next phase is known as diffusive combustion. The RoHR of the diffusive combustion phase is governed by the mixture of the evaporated fuel and the air process. During this phase, most parts of the pollutants are formed. Finally, at A950, B1500 and C2000 operation points (Fig. 4 (a)-(c)) a similar diffusive combustion process is shown, but with a double injection strategy. The effect of the pilot injection can be observed with the first RoHR peak separated from the main phase. It is also worth noting that by using a pilot injection, the ignition delay is considerably reduced, so that the premixed combustion stage is greatly attenuated. 

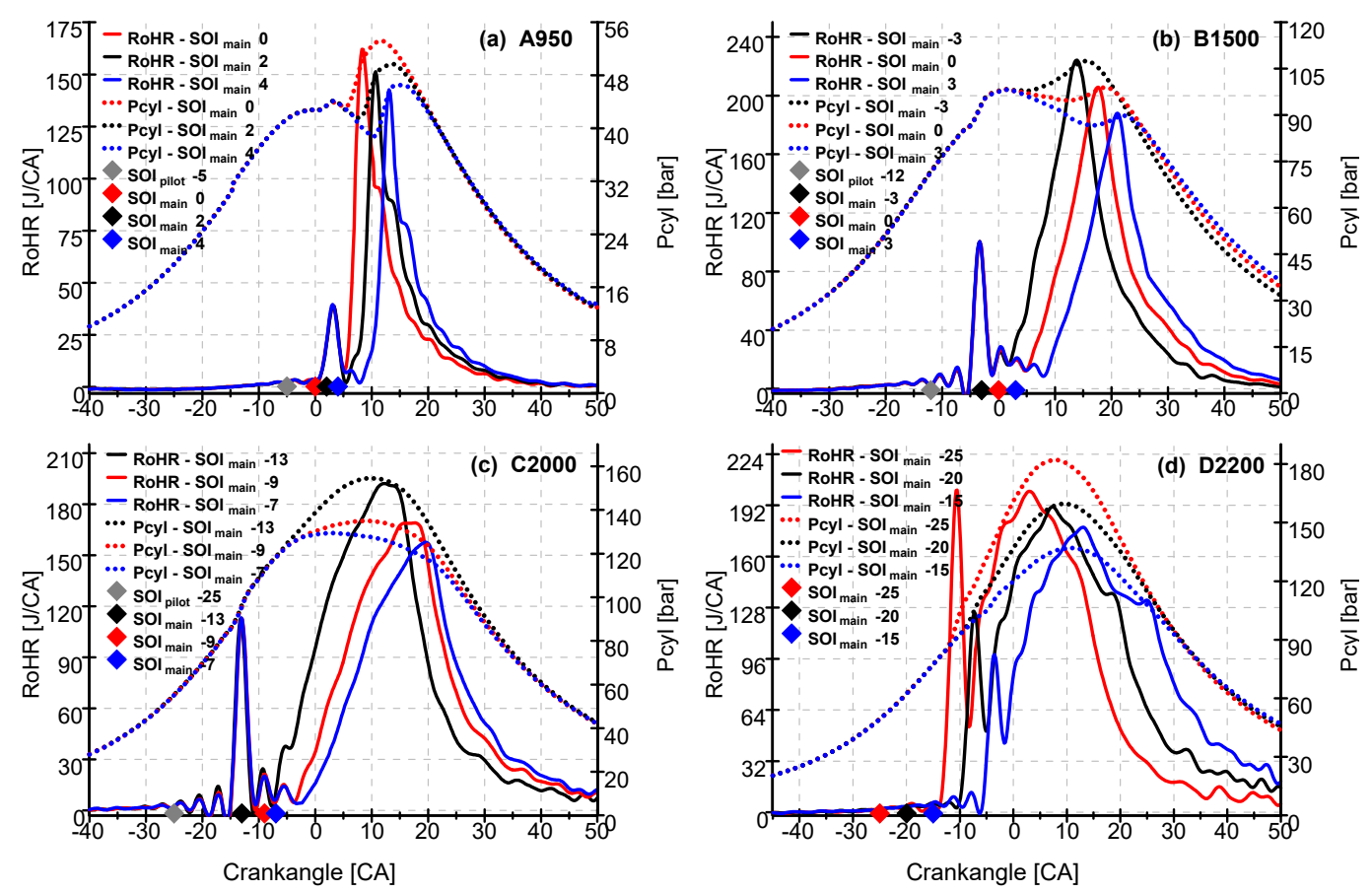

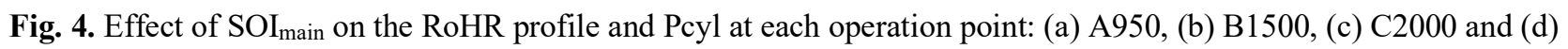
D2200 operation point.

Fig. 5 (a)-(d.2) shows the effect of SOImain variation on the main parameters of the combustion process: SoC (represented by CA10), combustion phase (represented by CA50) and maximum bulk gas temperature ( $\mathrm{T}$. Bulk Max). In addition, other parameters that allow the evaluation of combustion, such as CA90-CA10 and Mix. Time are also represented. As expected from the trend already observed in the RoHR profile and Pcyl (Fig. 4), the $\mathrm{SOI}_{\text {main }}$ delay causes a delay in the combustion phase during the expansion-stroke, to conditions where the temperature and pressure are lower due to the expansion of the cylinder volume. This can be observed with the delay of CA10 and CA50 (Fig. 5 (a)-(d)) and the decrease in T. Bulk Max (Fig. 5 (a.2)-(d.2)) in all operation points.

Finally, although the objective of this paper is not to evaluate the use of different injection strategies in terms of engine performance, the GIE analysis is important to identify whether the variation of the SOImain is really viable at each operation point. As shown in Fig. 5 (a.2)-(d.2), the GIE decreased its values with the SOI main delay in the four operation points. The results can be explained by the $\mathrm{SoC}$ and combustion phase delay. Due to the later combustion phase, the effective expansion ratio is reduced, which then causes the GIE to decrease. ${ }^{40}$ However, the effect of SOImain variations on this parameter is low (less than 5\%). 

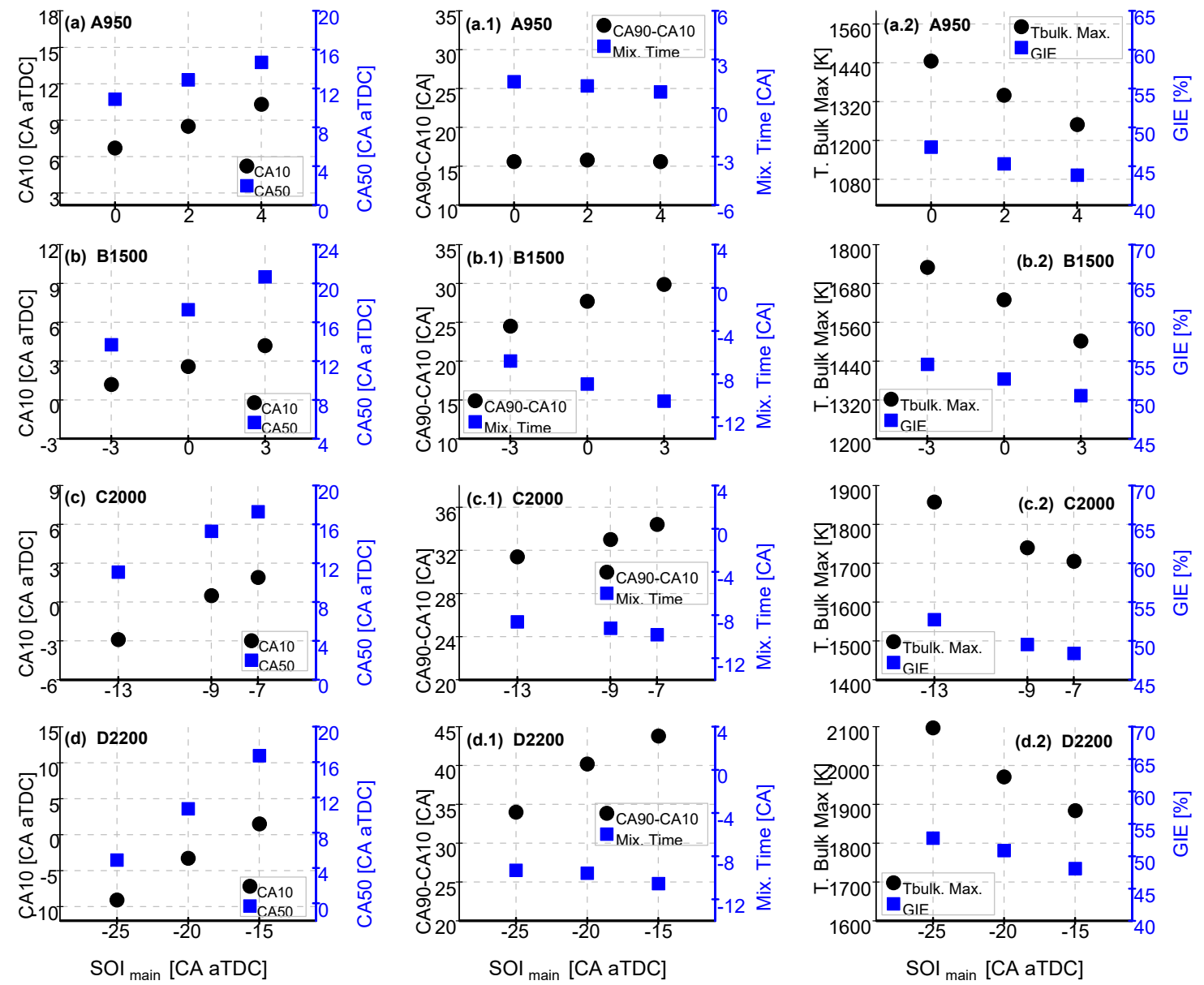

Fig. 5. Effect of $\mathrm{SOI}_{\text {main }}$ on combustion phase (CA10 and CA50), (CA90-CA10), Mix. Time, Max. bulk gas temperature and GIE: (a)-(a.2) A950, (b)-(b.2) B1500, (c)-(c.2) C2000 and (d)-(d.2) D2200 operation point.

With regard to the PN emissions, in Fig. 6 (a) the size distributions for the different $\mathrm{SOI}_{\text {mains }}$ at the A950 operation point are shown. As can be noted, the PSDs are formed by a bimodal structure, while as the SOImain is delayed, the particle concentration of accumulation-mode increases. This behavior is related to the complex balance between the formation and oxidation of particles during the combustion process. ${ }^{41,42}$ In these conditions, the deterioration of the particle oxidation process, due to the combustion phase delay where temperatures are lower, could be the main cause for the increase in the accumulation-mode particle concentration. The trend of the Pcyl curves and T. Bulk Max values in Fig. 4 (a) and Fig. 5 (a.2), respectively, confirm the decrease in the combustion temperatures with the $\mathrm{SOI}_{\text {main }}$ delay. Moreover, the $\mathrm{SOI}_{\text {main }}$ delay also provided a decrease in the nucleation-mode particle concentration (Fig. 6 (a.1)). This can be related by the decrease in the accumulationmode concentration, that is, with a reduction of the carbonaceous particles, the total surface will be smaller for the absorption of volatile condensates. ${ }^{43,44}$

At B1500 operation point, on the one hand, the SOI delay also slows down the combustion phase during the expansion-stroke (Fig. 5 (b)), reaching lower combustion temperatures (Fig. 5 (b.2)) and consequently the particle oxidation process is limited. On the other hand, this turns the combustion behavior more diffusive-like, a trend that is observed with the decrease in Mix. Time values (or its increase in absolute value). This indicates that the coexistence time between the fuel injection and the combustion process increases with the SOI delay, and the rise in CA90-CA10 also confirms this more diffusive nature. Fig. 5 (b.1) shows the behavior of both parameters. As a result of this increasingly diffusive combustion, the solid precursor particle formation increases, as shown in Fig. 6 (b.1), with the increase in PN emissions.

Similar results were obtained at the C2000 and D2200 operation points, as shown in Fig. (6 )-(c.1) and (d)(d.1). At both points, a significant increase in the accumulation-mode particle concentration was observed with the $\mathrm{SOI}_{\text {main }}$ delay. The increase in the diffusive nature of the combustion and the combustion phase delay, where 
lower in-cylinder temperatures are attained for the particles oxidation, favors to a great extent the PN emissions. This behavior is shown in Fig. 7, and at the four operation points we can observe how the GMDs increases with the increase in CA90-CA10 and the decrease in T. Bulk Max. This is due to the significant increase in the formation of primary particles in the combustion chamber that provides both parameters. With a greater amount of solid precursor particles, the surface growth and coagulation rates are favored, as a consequence, the soot agglomerates and the particle size increase. ${ }^{45,46}$
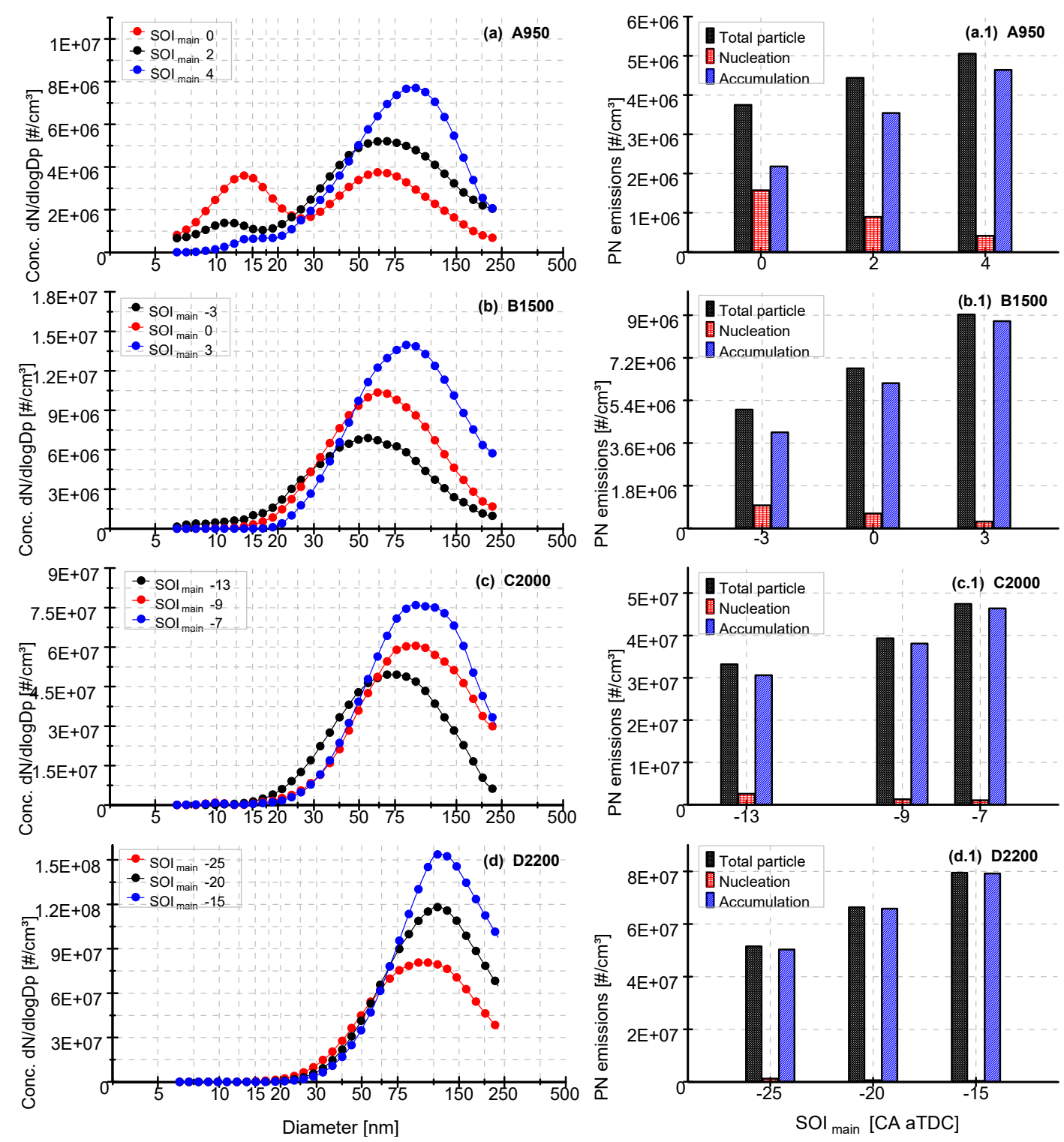

Fig. 6. Particle size distribution (PSD) and PN emissions for different $\mathrm{SOI}_{\text {main }}$ at each operation point: (a)-(a.1) A950, (b)-(b.1) B1500, (c)-(c.1) C2000 and (d)-(d.1) D2200 operation point. 

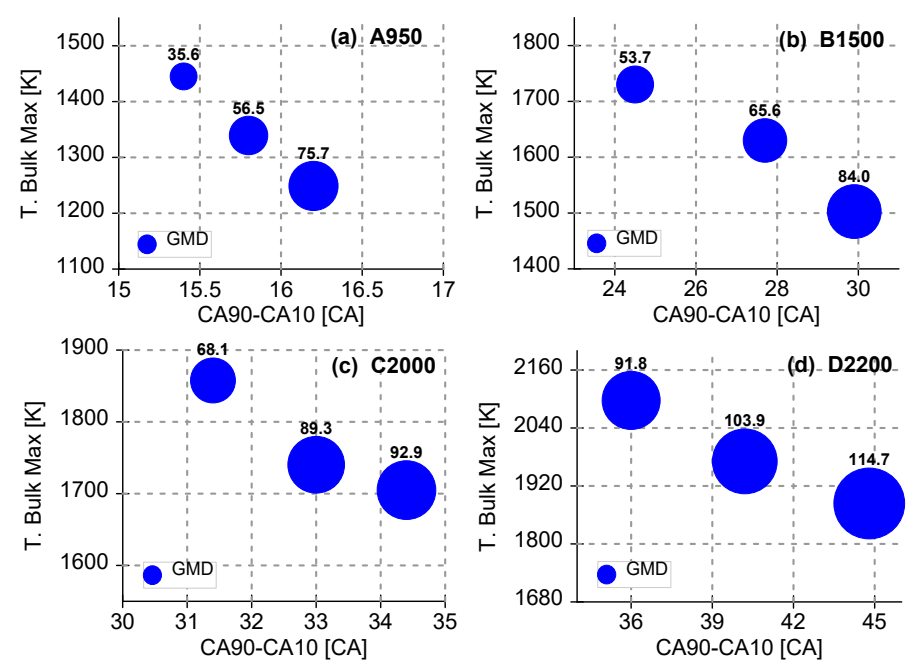

Fig. 7. Effect of combustion duration (CA90-CA10) and T. Bulk Max over the GMDs at each operation points, during the SOI main variations: (a) A950, (b) B1500, (c) C2000 and (d) D2200.

\subsection{Influence of injection pressure (IP)}

The effect of the parametric variation of IP on combustion process for the four operation points can be observed in the RoHR profiles and Pcyl in Fig. 8 and in the main parameter values of the combustion process in Fig. 9. In general terms, the IP reduction affects the combustion process, similar to the SOI delay, but with less of a prominent impact. In these operation conditions, where the amount of fuel injected at each operation point is not varied, the IP reduction provides a longer injection time and, consequently, an increase in combustion duration, in addition to a greater combustion phase delay relative to TDC that involve lower combustion temperatures. This is a trend that can be observed in Fig. 9 (a)-(d) with the CA50 delay and in Fig. 9 (a.1)-(d.1) and (a.2)-(d.2) with the increase in CA90-CA10 and the decrease in T. Bulk Max values respectively. As expected, the IP reduction also affected the engine efficiency, however the variations were very small as shown by the GIE values in Fig. 9 (a.2)-(d.2).
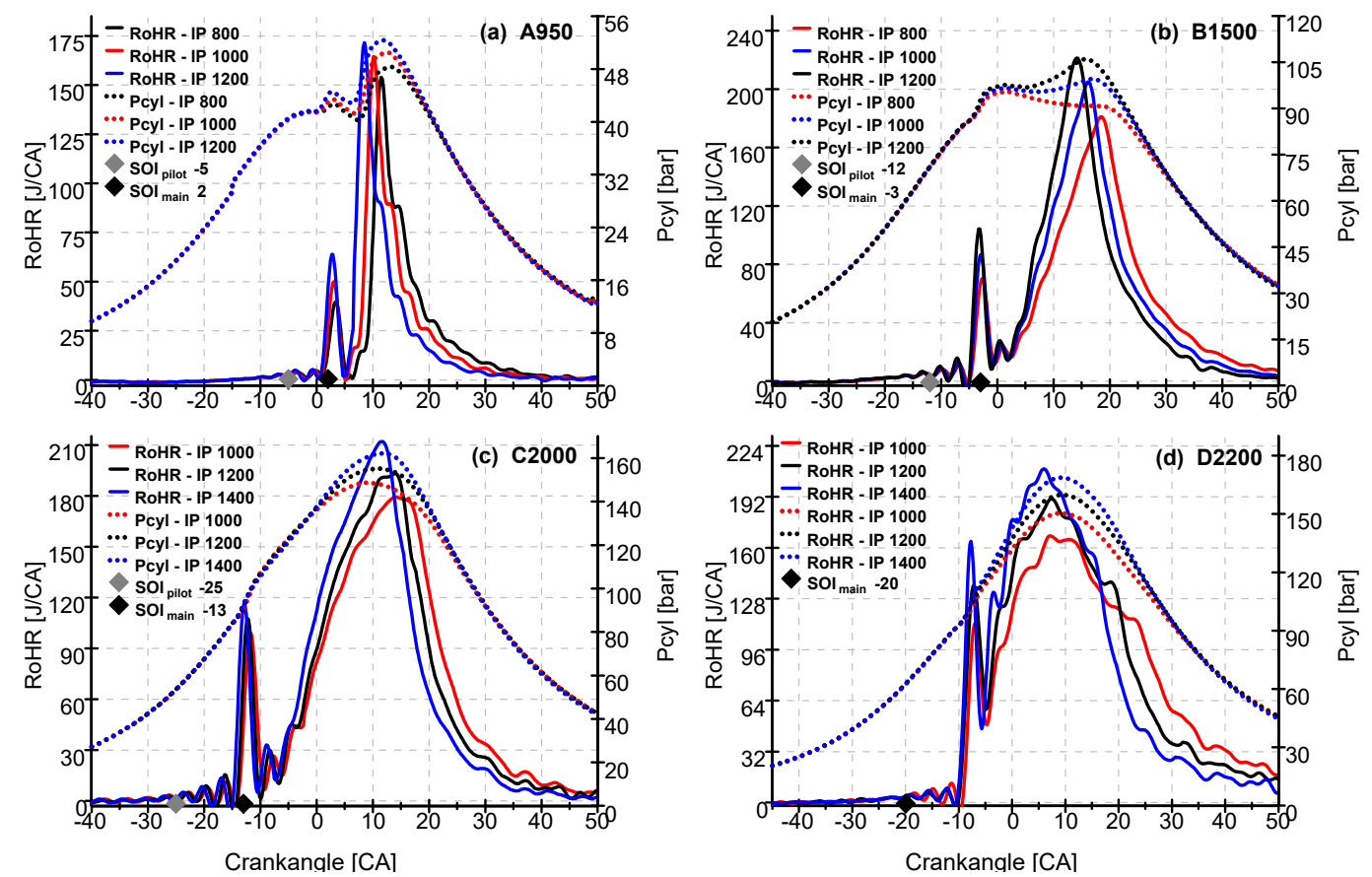

Fig. 8. Effect of IP on RoHR profile and Pcyl at each operation point: (a) A950, (b) B1500, (c) C2000 and (d) D2200 operation point. 

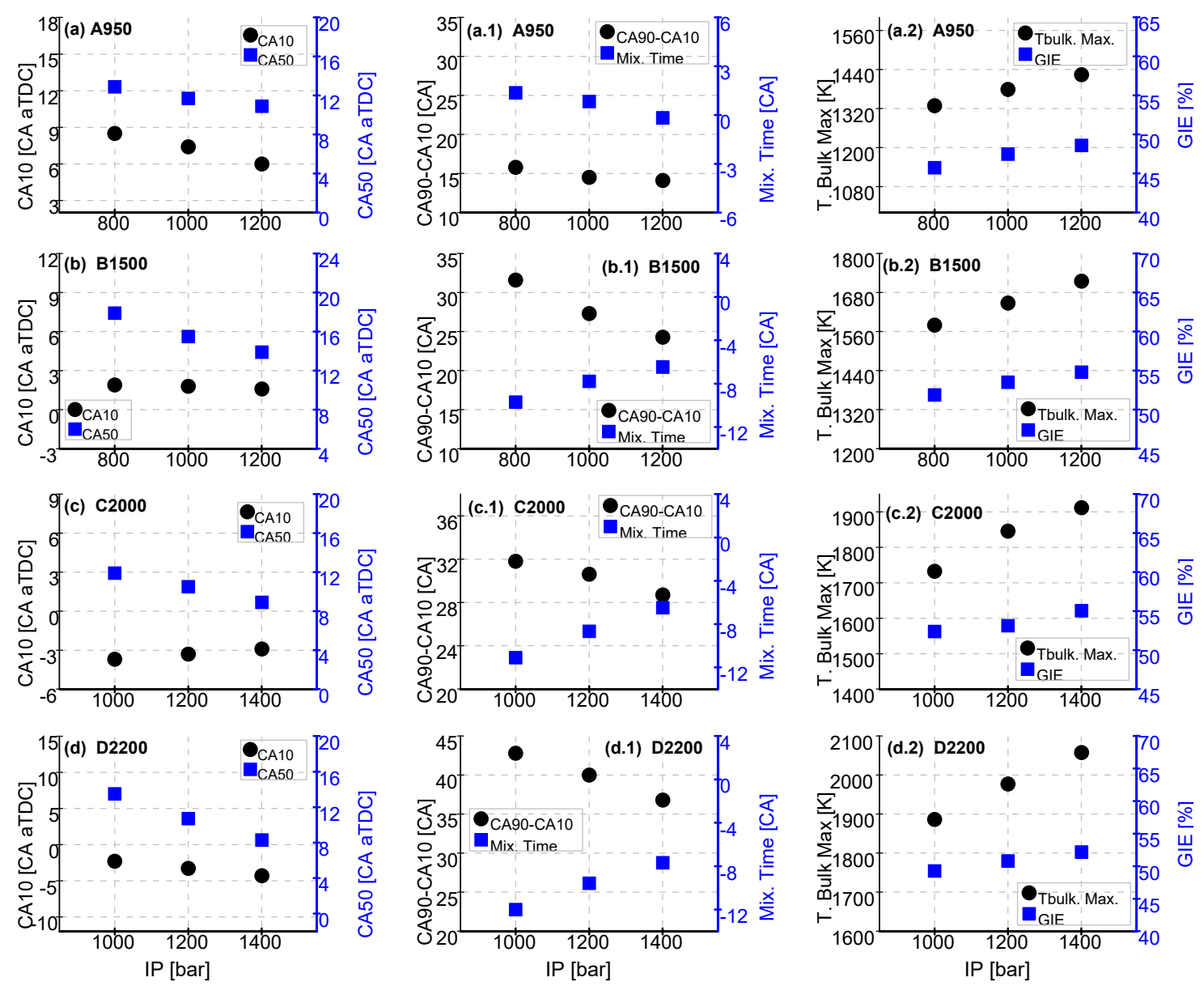

Fig. 9. Effect of IP on combustion phase (CA10 and CA50), (CA90-CA10), Mix. Time, Max. bulk gas temperature and GIE: (a)-(a.2) A950, (b)-(b.2) B1500, (c)-(c.2) C2000 and (d)-(d.2) D2200 operation point.

At the A950 operation point, a shift in the size distribution towards larger sizes and a reduction in the nucleation-mode particle concentration with the IP reduction is observed. This trend confirms the hypothesis that the nucleation-mode particle concentration increases with low concentrations of solid particles (accumulation-mode). Already, at the B1500, C2000 and D2200 operation points, the PN emissions increase with the IP reduction (Fig. 10 (b.1)-(d.1)) due to the increase in the diffusive nature of the combustion process and the decrease in combustion temperatures during the expansion-stroke.

Finally, the reduced variation in PN emissions for the different IPs allows an analysis between the operation points. At the A950 operation point, the reduced amount of fuel injected provides low combustion temperatures (Fig. 9 (a.2)), which greatly favors the condensation and coagulation of unburnt hydrocarbons and therefore the PSDs show a bimodal structure with the nucleation-mode and the accumulation-mode particle concentration. When shifting to B1500 operation point, the increase in the amount of fuel injected makes the combustion process more diffusive and combustion temperatures higher, which implies an increase in the soot precursor particles, leading to an increase in the accumulation-mode particle concentration and a considerable reduction in nucleation-mode particles, as shown in Fig. 10 (b.1). It is important to consider that the initial process of solid particles formation is favored by high temperatures, which is different from the process of particles oxidation as that is affected by a combustion process delay where combustion temperatures are lower. At the C2000 and D2200 operation points, the size distributions showed a behavior very similar to that of the B1500 operation point, but with much higher PN emissions and with size distributions increasingly displaced towards larger sizes, as shown in the GMD values in Fig. 11. This shows how the increase in the fuel mass, that occurs in these conditions, increases the particle concentration of accumulation-mode. The change in the size distribution and the increase in PN emissions were more evident when the engine speed increased. The main reasons for this behavior were the reduction of the time available for the mixture preparation and a deteriorate of the particles oxidation process. ${ }^{47}$ 

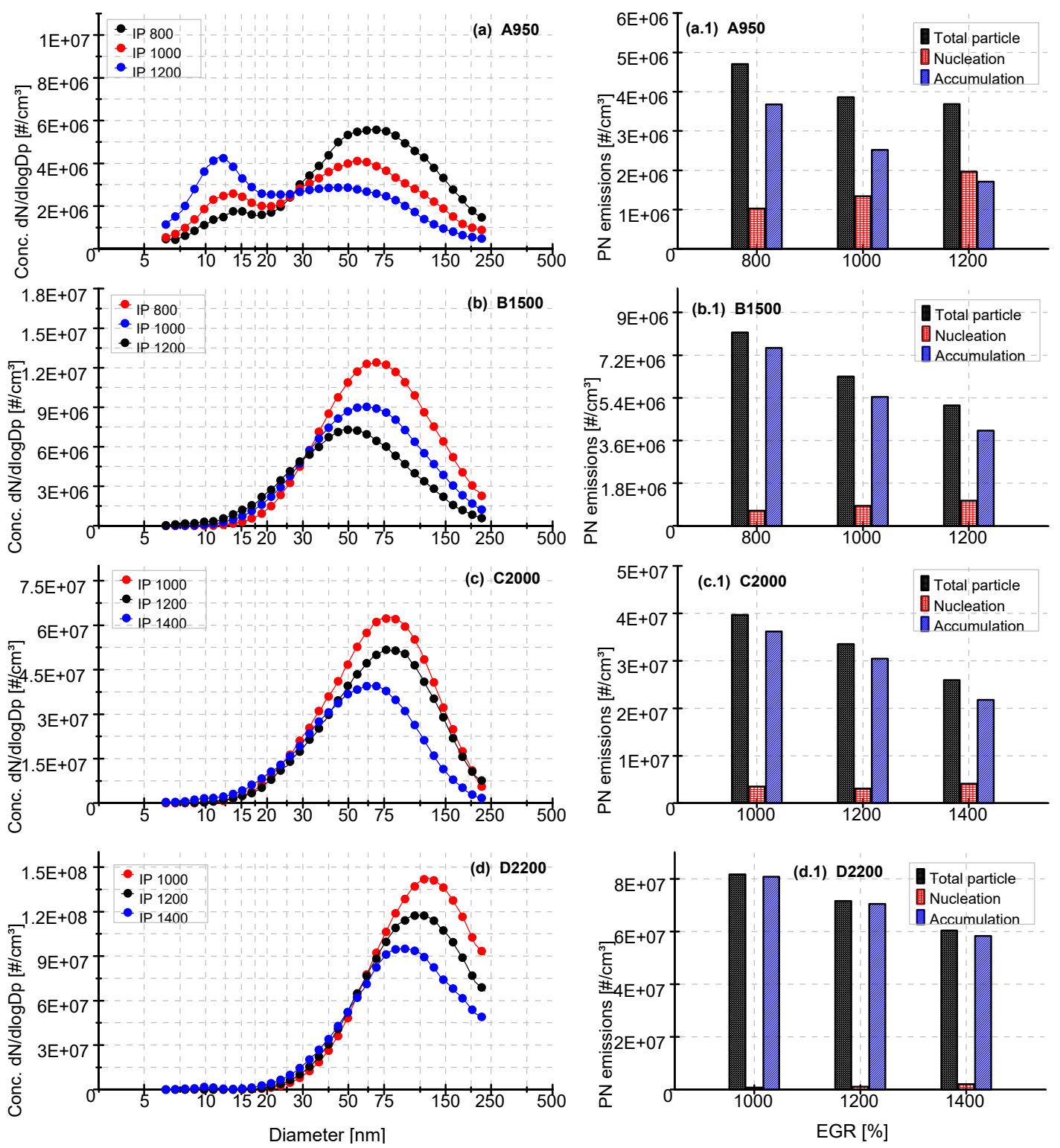

Fig. 10. Particle size distribution (PSD) and PN emissions for different IP at each operation point: (a)-(a.1) A950, (b)(b.1) B1500, (c)-(c.1) C2000 and (d)-(d.1) D2200 operation point.
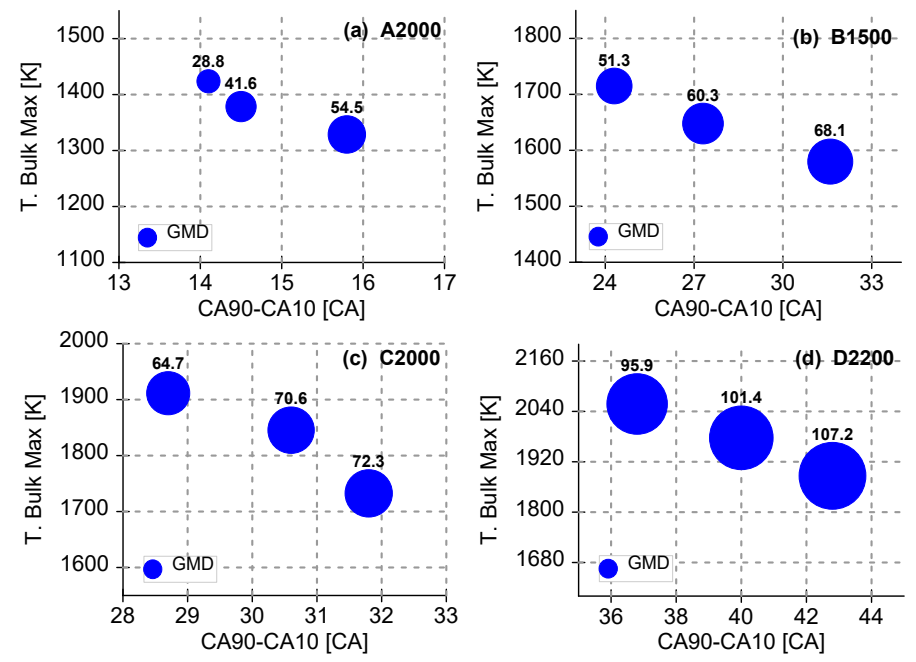

Fig. 11. Effect of combustion duration (CA90-CA10) and T. Bulk Max over the GMDs at each operation points, during the IP variations: (a) A950, (b) B1500, (c) C2000 and (d) D2200. 


\section{Conclusions}

The present study has focused on evaluating the main injection timing and injection pressure for PN emission control at four different steady-state operation points in terms of load and engine speed: $25 \%$ load and $950 \mathrm{r} / \mathrm{min}$ (A950), 50\% load and $1500 \mathrm{r} / \mathrm{min}$ (B1500), 75\% load and $2000 \mathrm{r} / \mathrm{min}$ (C2000) and 100\% load and $2200 \mathrm{r} / *^{*} \min (\mathrm{D} 2200)$ in a Euro VI DI diesel engine. This section summarizes the key conclusions extracted from this investigation.

At the A950 operation point, the $\mathrm{SOI}_{\text {main }}$ delay and the IP reduction delay the combustion phase during the expansion-stroke where lower temperatures are reached, affecting the particle oxidation process. Under these conditions, the accumulation-mode particle concentration decreases while the nucleation-mode particle concentration increases, in almost the same proportion. This is due to an increase in the absorption process of the volatile condensates on the solid particle surface, due to the greater quantity of these soot particles. At the B1500 operation point, the increase in the period of coexistence between the fuel injection and the combustion process, due to the SOI delay and the IP reduction, is the main factor due to the increase in PN emissions. This is aggravated in the C2000 and D2200 operation points, as was observed with the significant increase in the accumulation-mode particle concentration with $\mathrm{SOI}_{\text {main }}$ delay and IP reduction.

The load and the engine speed also showed a considerable impact on PN emissions, as could be observed when comparing the PSD between the four operation points. At the A950 operation point the size distributions showed a bimodal structure, the lower combustion temperatures due to the reduced load operation favor the formation process of volatile and non-volatile condensates and, consequently, a significant particle concentration of nucleation-mode. Already at the B1500 operating mode where it is necessary to inject a greater amount of fuel due to the increase in the load, the combustion behavior is more diffusive-like and consequently the formation of soot precursors is facilitated, considerably increasing the accumulation-mode particle concentration and decreasing the nucleation-mode particle concentration. This became more evident at high load and high speed, in the C2000 and D2200 operation points, where the size distributions were dominated by the accumulation-mode and with high PN emission values.

Finally, taking into account the formation process of other gaseous pollutants, such as NOx emissions that increase with high combustion temperatures, it is evident that some of these injection strategies that decrease the PN emissions may favor the NOx formation process. In this sense, as future work, an analysis of the impact of these injection strategies on gaseous compounds can be interesting in order to define injection settings that compensate the pollutant emissions in general. However, in order to better understand the PN emissions in modern DI diesel engines, this work shows how the injection parameters variations can significantly affect the concentrations and sizes of the particles without significant alterations in the engine efficiency.

\section{Acknowledgments}

This investigation has been funded by VOLVO Group Trucks Technology. The authors also acknowledge the Spanish economy and competitiveness ministry for partially supporting this research (HiReCo TRA201458870-R). 


\section{References}

1. Kemball-Cook S, Yarwood G, Johnson J, et al. Evaluating NOx emission inventories for regulatory air quality modeling using satellite and air quality model data. Atmos Environ 2015; 117: 1-8.

2. Paulin L, Hansel N. Particulate air pollution and impaired lung function. F1000Research 2016; 5: 201.

3. Hime N, Marks G, Cowie C. A Comparison of the Health Effects of Ambient Particulate Matter Air Pollution from Five Emission Sources. Int J Environ Res Public Health 2018; 15: 1206.

4. Johnson T, Joshi A. Review of Vehicle Engine Efficiency and Emissions. SAE Int J Engines 2018; 11: 13071330.

5. Wu Z, Rutland CJ, Han Z. Numerical optimization of natural gas and diesel dual-fuel combustion for a heavyduty engine operated at a medium load. Int J Engine Res 2018; 19: 682-696.

6. Lapuerta M, Hernández JJ, Rodríguez-Fernández J, et al. Emission benefits from the use of n-butanol blends in a Euro 6 diesel engine. Int J Engine Res 2018; 19: 1099-1112.

7. Momenimovahed A, Liu F, Thomson KA, et al. Effect of fuel composition on properties of particles emitted from a diesel-natural gas dual fuel engine. Int J Engine Res 2019; DOI: 10.1177/1468087419846018.

8. Chilumukuru K, Gupta A, Ruth M, et al. Aftertreatment Architecture and Control Methodologies for Future Light Duty Diesel Emission Regulations. SAE Int J Engines 2017; 10: 2017-01-0911.

9. Bermúdez V, Luján JM, Piqueras P, et al. Pollutants emission and particle behavior in a pre-turbo aftertreatment light-duty diesel engine. Energy 2014; 66: 509-522.

10. Lapuerta M, Ramos Á, Fernández-Rodríguez D, et al. High-pressure versus low-pressure exhaust gas recirculation in a Euro 6 diesel engine with lean-NOx trap: Effectiveness to reduce NOx emissions. Int J Engine Res 2019; 20: 155-163.

11. Rakopoulos CD, Rakopoulos DC, Mavropoulos GC, et al. Investigating the EGR rate and temperature impact on diesel engine combustion and emissions under various injection timings and loads by comprehensive two-zone modeling. Energy 2018; 157: 990-1014.

12. Du W, Lou J, Yan Y, et al. Effects of injection pressure on diesel sprays in constant injection mass condition. Appl Therm Eng 2017; 121: 234-241.

13. Nishida K, Zhu J, Leng X, et al. Effects of micro-hole nozzle and ultra-high injection pressure on air entrainment, liquid penetration, flame lift-off and soot formation of diesel spray flame. Int J Engine Res 2017; 18: 51-65.

14. Yamasaki Y, Ikemura R, Kaneko S. Model-based control of diesel engines with multiple fuel injections. Int $J$ Engine Res 2018; 19: 257-265.

15. Korkmaz M, Ritter D, Jochim B, et al. Effects of injection strategy on performance and emissions metrics in a diesel/methane dual-fuel single-cylinder compression ignition engine. Int J Engine Res 2019; DOI: $10.1177 / 1468087419836586$.

16. Giechaskiel B, Schiefer E, Schindler W, et al. Overview of Soot Emission Measurements Instrumentation: From Smoke and Filter Mass to Particle Number. SAE Int J Engines 2013; 6: 2013-01-0138.

17. Seinfeld JH, Pandis SN. Atmospheric chemistry and physics : from air pollution to climate change. 2 nd ed. Hoboken, New Jersey: J. Wiley, 2006.

18. Dickau M, Olfert J, Stettler MEJ, et al. Methodology for quantifying the volatile mixing state of an aerosol. Aerosol Sci Technol 2016; 50: 759-772.

19. Lähde T, Rönkkö T, Virtanen A, et al. Heavy Duty Diesel Engine Exhaust Aerosol Particle and Ion Measurements. Environ Sci Technol 2009; 43: 163-168.

20. Saxena MR, Maurya RK. Effect of premixing ratio, injection timing and compression ratio on nano particle emissions from dual fuel non-road compression ignition engine fueled with gasoline/methanol (port injection) and diesel (direct injection). Fuel 2017; 203: 894-914.

21. Gao J, Kuo T-W. Toward the accurate prediction of soot in engine applications. Int J Engine Res 2018; DOI: 10.1177/1468087418773937.

22. Zhang Y, Ghandhi J, Rothamer D. Comparisons of particle size distribution from conventional and advanced compression ignition combustion strategies. Int J Engine Res 2018; 19: 699-717.

23. Lapuerta M, Armas O, Gómez A. Diesel Particle Size Distribution Estimation from Digital Image Analysis. Aerosol Sci Technol 2003; 37: 369-381.

24. Agarwal AK, Gupta T, Kothari A. Particulate emissions from biodiesel vs diesel fuelled compression ignition engine. Renew Sustain Energy Rev 2011; 15: 3278-3300.

25. Bai J, Qiao X. Crankcase gaseous and particle emissions in common rail diesel engine. Int J Engine Res 2016; 
17: 179-192.

26. Reijnders J, Boot M, de Goey P. Particle nucleation-accumulation mode trade-off: A second diesel dilemma? $J$ Aerosol Sci 2018; 124: 95-111.

27. Bonatesta F, Chiappetta E, La Rocca A. Part-load particulate matter from a GDI engine and the connection with combustion characteristics. Appl Energy 2014; 124: 366-376.

28. Baumgard KJ, Johnson JH. The Effect of Fuel and Engine Design on Diesel Exhaust Particle Size Distributions. In: SAE Technical Paper 960131. DOI: 10.4271/960131.

29. Bertola A, Schubiger R, Kasper A, et al. Characterization of Diesel Particulate Emissions in Heavy-Duty DIDiesel Engines with Common Rail Fuel Injection Influence of Injection Parameters and Fuel Composition. In: SAE Technical Paper 2001-01-3573. DOI: 10.4271/2001-01-3573.

30. Desantes JM, Bermúdez V, García A, et al. A Comprehensive Study of Particle Size Distributions with the Use of PostInjection Strategies in DI Diesel Engines. Aerosol Sci Technol 2011; 45: 1161-1175.

31. Li X, Guan C, Luo Y, et al. Effect of multiple-injection strategies on diesel engine exhaust particle size and nanostructure. J Aerosol Sci 2015; 89: 69-76.

32. Korkmaz M, Ritter D, Jochim B, et al. Effects of injection strategy on performance and emissions metrics in a diesel/methane dual-fuel single-cylinder compression ignition engine. Int J Engine Res 2019; DOI: 10.1177/1468087419836586.

33. Benajes J, García A, Monsalve-Serrano J, et al. Evaluating the reactivity controlled compression ignition operating range limits in a high-compression ratio medium-duty diesel engine fueled with biodiesel and ethanol. Int J Engine Res 2017; 18: 66-80.

34. Kakaee A-H, Nasiri-Toosi A, Partovi B, et al. Effects of piston bowl geometry on combustion and emissions characteristics of a natural gas/diesel RCCI engine. Appl Therm Eng 2016; 102: 1462-1472.

35. Kasper M. The Number Concentration of Non-Volatile Particles - Design Study for an Instrument According to the PMP Recommendations. In: SAE Technical Paper. 2004-01-0960. DOI: 10.4271/2004-01-0960.

36. Desantes JM, Bermúdez V, Pastor J V, et al. Methodology for measuring exhaust aerosol size distributions from heavy duty diesel engines by means of a scanning mobility particle sizer. Meas Sci Technol 2004; 15: 20832098.

37. Desantes JM, Bermúdez V, Molina S, et al. Methodology for measuring exhaust aerosol size distributions using an engine test under transient operating conditions. Meas Sci Technol 2011; 22: 115101.

38. Payri F, Olmeda P, Martín J, et al. A complete 0D thermodynamic predictive model for direct injection diesel engines. Appl Energy 2011; 88: 4632-4641.

39. Benajes J, López JJ, Novella R, et al. ADVANCED METHODOLOGY FOR IMPROVING TESTING EFFICIENCY IN A SINGLE-CYLINDER RESEARCH DIESEL ENGINE. Exp Tech 2008; 32: 41-47.

40. Liu Q, Fu J, Zhu G, et al. Comparative study on thermodynamics, combustion and emissions of turbocharged gasoline direct injection (GDI) engine under NEDC and steady-state conditions. Energy Convers Manag 2018; 169: 111-123.

41. Musculus MP, Dec JE, Tree DR. Effects of Fuel Parameters and Diffusion Flame Lift-Off on Soot Formation in a Heavy-Duty DI Diesel Engine. In: SAE Technical Paper, 2002-01-0889. DOI: 10.4271/2002-01-0889.

42. Seong HJ, Boehman AL. Studies of soot oxidative reactivity using a diffusion flame burner. Combust Flame 2012; 159: 1864-1875.

43. Desantes JM, Bermúdez V, García JM, et al. Effects of current engine strategies on the exhaust aerosol particle size distribution from a Heavy-Duty Diesel Engine. J Aerosol Sci 2005; 36: 1251-1276.

44. Lucachick G, Curran S, Storey J, et al. Volatility characterization of nanoparticles from single and dual-fuel low temperature combustion in compression ignition engines. Aerosol Sci Technol 2016; 50: 436-447.

45. Mohankumar S, Senthilkumar P. Particulate matter formation and its control methodologies for diesel engine: A comprehensive review. Renew Sustain Energy Rev 2017; 80: 1227-1238.

46. Burtscher H. Physical characterization of particulate emissions from diesel engines: a review. J Aerosol Sci 2005; 36: 896-932.

47. Hageman MD, Rothamer DA. Impacts of combustion phasing, load, and speed on soot formation in sparkignition engines. Int J Engine Res 2019; DOI: 10.1177/1468087419836584. 